\title{
Degree Spilliting Analysis for Polynomials Developed for Electrical Systems
}

\author{
P. Jagadeeswari
}

Abstract: In this paper, we investigate the degree splitting graphs of $P_{n}(n>3)$, comb graph, $\left(K_{1 n}^{(1)} K_{1 n}^{(2)}\right), C_{m} \Theta \overline{K_{m}}, S\left(K_{1, n}\right)$ and Tadpole graph are Square difference graph (SDG).

Keywords: Square difference labeling (SDL), comb graph, tadpole graph, degree splitting AMS classification: $05 C 78$

\section{INTRODUCTION}

The Square difference labelling were established by Shiama [8]. The degree splitting concept was introduced in [5]. P. Maya and Nicholas proved that the degree splitting of some graphs are I - cordial [4]. Domination in degree splitting graphs were established by B. Basavangoval et al. [1]. Mean labelling on degree splitting graph of star graph was investigated in [9]. Square difference labelling of some special graphs were proved in [3]. In this paper, we use simple, finite and undirected graph and we follows notation, terminology from $[2,3,6]$ prove that the degree splitting graph of various graphs are Square difference graph.

\section{MAIN RESULTS}

Definition 2.1.1. [8]

A graph $G=(p, q)$ is said to be a Square difference graph if it admits a bijective function $\mathrm{g}: V(G) \rightarrow\{0,1,2, \ldots \ldots p$ - 1$\}$ such that the induced function $g^{*}: E(G) \rightarrow N$ given by $g{ }^{*}(x y)$ $=\left|[g(x)]^{2}-[g(y)]^{2}\right|$ are all distinct, $\forall x y \in E(G)$.

Definition 2.1.2. [5]

The degree splitting graph is obtained from $\mathrm{G}$ by adding vertices $w_{l}, w_{2}, \ldots w_{t}$ and joining to each vertex of $S_{i}, 1 \leq i \leq t$ which is a set of vertices having atleast two vertices of the same degree and is denoted by $D S(G)$.

\section{Definition 2.1.3 [7]}

A tadpole $T(n, m)$ is the graph procured by appending a path $P_{t}$ to cycle $C_{n}$.

\section{Theorem 2.1.}

The graph $D S\left(P_{n}\right)$ is Square difference graph.

Proof:

Consider $\operatorname{DS}\left(\mathrm{P}_{\mathrm{n}}\right)(\mathrm{n}>3)$ be the graph with

$$
\mathrm{E}=
$$

$\left\{u_{i} u_{i+1}, w_{1}, u_{1}, w_{1} u_{n} \mid 1 \leq i \leq n-1\right\} \cup$

$\left\{w_{2} u_{i} \mid 2 \leq i \leq n-1\right\}$

Clearly, $|V(G)|=n+2$, and

$$
|E(G)|=2 n-1
$$

Now, define the vertex function as $f: V \rightarrow\{0,1, \ldots n+1\}$ as $f(\mathrm{u})=i-1,1 \leq i \leq n$

Revised Manuscript Received on December 16, 2019

*P. Jagadeeswari Department of Science and Humanities, BIHER, Chennai, Tamil Nadu, India. Email: jayaaishu@ yahoo.com

$$
\mathrm{V}=\left\{u_{i}, w_{1}, w_{2} \mid 1 \leq i \leq n\right\} \text { and }
$$

$$
\begin{aligned}
& f\left(w_{1}\right)=n \\
& f\left(w_{2}\right)=n+1
\end{aligned}
$$

Then, the induced edge labels $f^{*}$ are given below:

$$
\begin{aligned}
& f^{*}\left(u_{i} u_{i+1}\right)=2 i-1 \\
& f^{*}\left(w_{1} u_{1}\right)=n^{2} \\
& f^{*}\left(w_{1} u_{n}\right)=2 n-1,
\end{aligned}
$$

when $n$ is even, for $i=2,3, \ldots n-1$

$$
f^{*}\left(w_{2} u_{i}\right)=\left\{\begin{array}{l}
0(\bmod 2), i \text { is even } \\
1(\bmod 2), i \text { is odd }
\end{array}\right\}
$$

when $n$ is odd,

$$
f^{*}\left(w_{2} u_{i}\right)=\left\{\begin{array}{l}
1(\bmod 2), i \text { is even } \\
0(\bmod 2), i \text { is odd }
\end{array}\right\}
$$

Thus, the entire $2 n-1$ edge labeling are all distinct. Hence the theorem.

\section{Example 2.1.}

The SDG of DS( $\left.\mathrm{P}_{9}\right)$

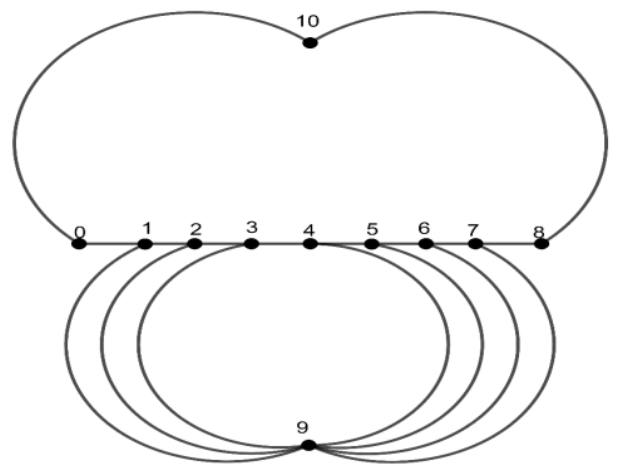

Figure 1. SDG of DS( $\left.\mathrm{P}_{9}\right)$

Theorem 2.2.

The Degree splitting graph of $P_{m} \odot K_{l}$ admits Square difference labeling.

Proof:

Let $G=D S\left(P_{m} \odot K_{l}\right)$ with the vertex set

$V(G)=\left\{u_{i}, v_{i} w_{1}, w_{2}, w_{3} \mid 1 \leq i \leq m\right\}$ and $E(G)=$

$\left\{u_{i} u_{i+1} / 1 \leq i \leq m-1\right\} \cup\left\{u_{i} v_{i} \mid 1 \leq i \leq m\right\} \cup$

$$
\left\{w_{1} v_{i_{i}}, w_{2} u_{i} \mid i=2,3, \ldots m-1\right\} \cup
$$

$\left\{w_{2} u_{1}, w_{2} u_{n}\right\}$

It's clear that, $|V(G)|=2 m+3$ and $|E(G)|=4 m-1$.

Now, the vertex valued function $f$ as:

$$
\begin{aligned}
& f\left(u_{i}\right)=2(i-1) \\
& f\left(v_{i}\right)=2 i-1 \\
& f\left(w_{1}\right)=2 m \\
& f\left(w_{2}\right)=2 m+1 \\
& f\left(w_{3}\right)=2 m+2
\end{aligned}
$$

Consider, the edge labeling $f^{*}$ as:

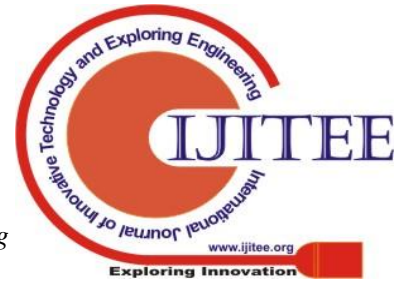




\section{Degree Spilliting Analysis for Polynomials Developed for Electrical Systems}

$$
\begin{aligned}
& f^{*}\left(u_{i} u_{i+1}\right)=8 i-4 \\
& f^{*}\left(u_{i} v_{i}\right)=4 i-3 \\
& f^{*}\left(w_{1} v_{i}\right)=\left\{\begin{array}{l}
7(\bmod 8), n \text { is even } \\
3(\bmod 8), n \text { is odd }
\end{array}\right\} \\
& f^{*}\left(w_{2} u_{i}\right)=\left\{\begin{array}{l}
5(\bmod 8), i \text { is even } \\
1(\bmod 8), \text { i is odd }
\end{array}\right\} \\
& f^{*}\left(w_{2} u_{1}\right) \equiv 0(\bmod 8) \\
& f^{*}\left(w_{2} u_{n}\right)=(2 m+2)^{2}
\end{aligned}
$$

Therefore, both the vertex and edge labeling are satisfies the SD labeling. Hence the theorem.

\section{Example: 2.2.}

SDG of $P_{9} \odot K_{1}$

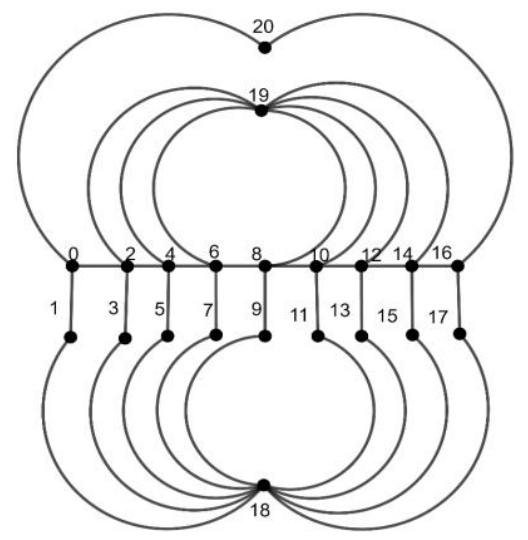

Figure 2.2. $P_{9} \odot K_{l}$

\section{Theorem 2.3.}

The graph DS $\left(K_{1 n}^{(1,1)} K_{1, n}^{(02)}\right)$ is Square difference graph.

\section{Proof:}

Consider the graph $\operatorname{DS}\left(K_{1 n}^{[1]} K_{1 n}^{([2)}\right)$ with

$V\left[D S\left(K_{1, n}^{[1]} K_{1, n}^{(\mathfrak{L})}\right)\right]=\left\{x_{i}, y_{i} / 1 \leq i \leq n\right\} \cup \quad\{x, y\} \cup$ $\left\{w_{1}, w_{2}, w_{3}\right\}$

and $E[D S$

$$
\left.\left(K_{1, n}^{[1(1)} K_{1, n}^{(2)}\right)\right]
$$

$\left\{x x_{i}, y_{i} / 1 \leq i \leq n\right\} \cup\left\{w_{1} y_{i}, w_{1} x_{i}\right\} \cup\left\{w_{2} x, w_{2} y\right\}$

The number of vertices and edges are denoted as $2 n+4$ and $4 n+4$ respectively.

Let the vertex labeling $f: \mathrm{V} \rightarrow\{0,1, \ldots 2 \mathrm{n}+3\}$ is given below:

$$
\begin{aligned}
& f\left(w_{1}\right)=0 \\
& f\left(w_{2}\right)=2 n+3 \\
& f\left(w_{3}\right)=2 n+4 \\
& f(x)=2 \\
& f(\mathrm{y})=1 \\
& f\left(x_{i}\right)=i+2 \\
& f\left(y_{i}\right)=n+i+2
\end{aligned}
$$

and the induced edge labels are

$$
\begin{aligned}
& f^{*}\left(x x_{i}\right)=i^{2}+4 i \\
& f^{*}\left(y y_{i}\right)=(n+i+2)^{2}-1 \\
& f^{*}\left(w_{1} x_{i}\right)=(i+1)^{2} \\
& f^{*}\left(w_{1} y_{i}\right)=(n+i+2)^{2} \\
& f^{*}\left(w_{2} x\right)=(2 n+3)^{2}-4 \\
& f^{*}\left(w_{2} y\right)=(2 n+4)^{2}-1
\end{aligned}
$$

Thus, no edge labeling are same. Therefore, the theorem is proved.

\section{Example: 2.3 .}

Square difference labeling for $\operatorname{DS}\left(K_{15}^{[1]} K_{15}^{(2)}\right)$.

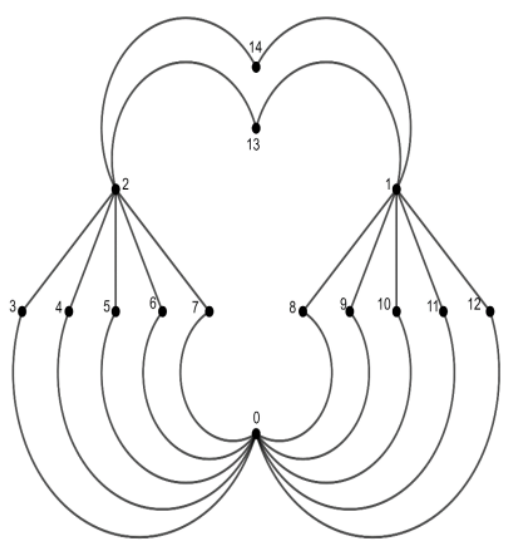

Figure 2.3. DS $\left(K_{1,5}^{[1]} K_{1,5}^{(2)}\right)$

Theorem 2.4.

DS $\left(\mathrm{C}_{\mathrm{m}} \odot \overline{K_{n}}\right)$ admits SDL.

Proof:

Consider the vertex and edge set of the degree splitting graph of $\mathrm{C}_{\mathrm{m}} \Theta \overline{K_{n}}$ as

$$
\begin{aligned}
& V\left[D S\left(C_{m} \odot \overline{K_{n}}\right)\right]=V_{l} \cup V_{2} \cup V_{3}, \text { where } \\
& V_{1}=\left\{v_{i} / 1 \leq i \leq m\right\} \\
& V_{2}=\left\{v_{j}^{(m)} / 1 \leq j \leq n, 1 \leq r \leq i\right\} \\
& V_{3}=\{x, y\}
\end{aligned}
$$

And $\mathrm{E}\left[D S\left(\mathrm{C}_{\mathrm{m}} \odot \overline{K_{n}}\right)\right]=E_{l} \cup E_{2} \cup E_{3}$, where

$$
\begin{aligned}
& E_{1}=\left\{v_{i} v_{i+1} / 1 \leq i \leq m-1\right\} \\
& E_{2}=\left\{v_{i} v_{j}^{(m)} / 1 \leq i \leq n, 1 \leq r \leq i\right\} \\
& E_{3}=\left\{v_{n} v_{1}, x v_{j}^{(m)}, y v_{i}\right\}
\end{aligned}
$$

Now, the bijective function $f$ on $v$ is defined as:

$$
\begin{aligned}
& f\left(v_{i}\right)=i+1 \\
& f\left(v_{j}^{(m)}\right)=m+j+1+(r-1) n \\
& f(x)=0 \\
& f(y)=1
\end{aligned}
$$

The induced function $f^{*}$ for the above vertex labeling is given below:

$$
\begin{aligned}
& f^{*}\left(v_{i} v_{i+1}\right)=2 i+3 \\
& f^{*}\left(v_{m} v_{l}\right)=(m+1)^{2}-4 \\
& f^{*}\left(v_{i} v_{j}^{(w)}\right)=\left|(i+1)^{2}-(m+j+1+(r-1) n)^{2}\right| \\
& f^{*}\left(x v_{j}^{(m)}\right)=[m+j+1+(r-1) n]^{2} \\
& f^{*}\left(y v_{i}\right)=(i+1)^{2}
\end{aligned}
$$

Clearly, the induced function $f^{*}$ are all distinct. Hence, the theorem.

\section{Example 2.4.}

The degree splitting graph of $\mathrm{C}_{\mathrm{m}} \mathrm{\Theta} \overline{K_{n}}$ 
Figure 2.4. $D S\left(\mathrm{C}_{4} \odot \overline{K_{3}}\right)$

\section{Theorem 2.5.}

The degree splitting graph of Tadpole $T(n, m)$ admits square difference labeling.

Proof:

$$
\begin{aligned}
& \text { Let } G=D S[T(n, m)] \text { with } \\
& V(G)=\left\{v_{i} \mid 1 \leq j \leq n+m\right\} \cup\{x\}
\end{aligned}
$$

$$
\text { and } \quad E(\mathrm{G})=\quad\left\{v_{i} v_{i+1} / 1 \leq j \leq m+n-2\right\} \cup
$$
$\left\{v_{n+m-1} v_{m}\right\} \cup\left\{x v_{j}\right\}$

It is seen clear that the number of vertices and number of edges are $n+m$ and $2(m+n)-4$ respectively. Let the vertex valued function $g: V \rightarrow\left\{0,1_{n} \ldots n+m-1\right\}$ be defined as follows:

$$
\begin{aligned}
& g\left(v_{j}\right)=j-1 \\
& g(x)=n+m-1
\end{aligned}
$$

and the induced function $g^{*}: E(G) \rightarrow N$ satisfies the condition of SD Labeling. Thus the edge labels are defined as

$$
\begin{aligned}
& g^{*}\left(v_{j} v_{i+1}\right)=2 j-1 \\
& g^{*}\left(v_{n+m-1} v_{m}\right)=\left[g\left(v_{n+m-1}\right)\right]^{2}-\left[g\left(\left(v_{m}\right)\right]^{2}\right. \\
& g^{*}\left(x v_{j}\right)=[n+m-1]^{2}-[2 j-1]^{2}
\end{aligned}
$$

Thus, the entire edge labeling are distinct. Therefore, $D S[T(n, m)]$ is SDG.

\section{Example 2.5.}

SDG of Degree splitting graph of $T(4,6)$.

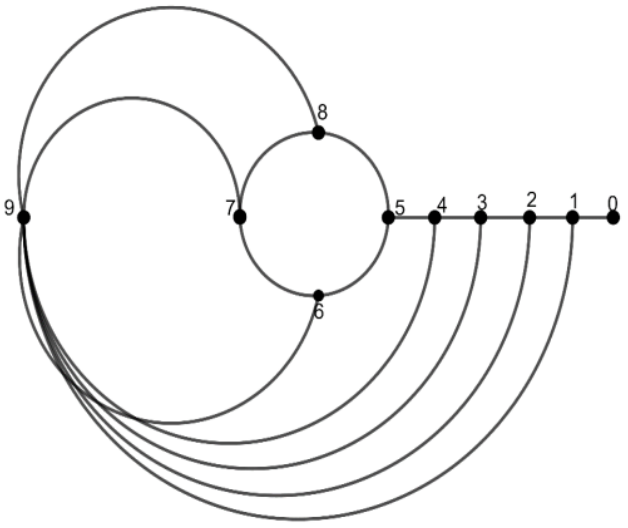

Figure 2.5. $D S[T(4,6)]$

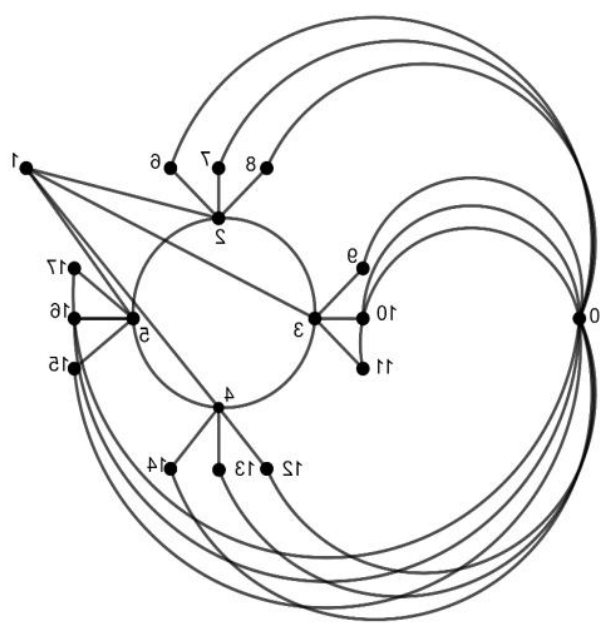

The degree splitting of subdivision of $K_{1, n}$ admits Square difference graph.

\section{Proof:}

Consider the graph $D S\left(S\left(K_{1, n}\right)\right)$ with

$$
\begin{aligned}
& V=\left\{u_{i j}, w_{j}, x, y, z \mid 1 \leq j \leq n\right\} \text { and } \\
& E=\left\{u_{j} w_{j}, x u_{j}, y w_{j}, z u_{j} / 1 \leq j \leq n\right\}
\end{aligned}
$$

Now, define the function $f$ as

$$
\begin{aligned}
& f(z)=0 \\
& f(y)=1 \\
& f(x)=2 \\
& f\left(u_{j}\right)=2 j+2 \\
& f\left(w_{j}\right)=2 j+1
\end{aligned}
$$

and the induced edge function $f^{*}$ receive labeling as:

$$
\begin{aligned}
& f^{*}\left(u_{j} w_{i}\right)=4 j+3 \\
& f^{*}\left(x u_{i}\right)=[2 j+2]^{2}-4 \\
& f^{*}\left(y w_{i}\right)=[2 j+2]^{2}-1 \\
& f^{*}\left(z u_{j}\right)=[2 j+2]^{2}
\end{aligned}
$$

Hence $f^{*}\left(e_{i}\right) \neq f^{*}\left(e_{i}\right), \forall e_{i j}, e_{j} \in E(G)$. Thus, all the edge labeling are not same. Therefore, the degree splitting graph of subdivision of $K_{1 n}$ is square difference graph.

Example: 2.6.

Square Difference Graph of $S\left(K_{1,5}\right)$.

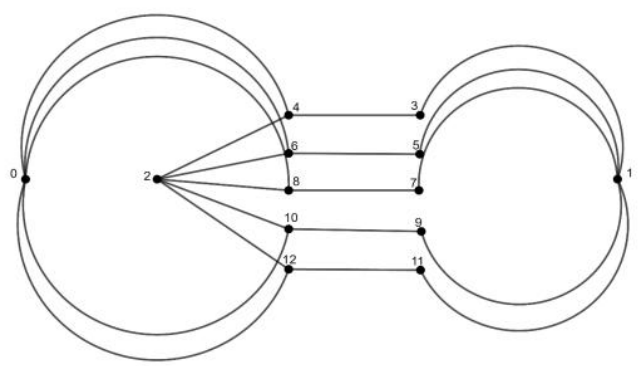

Figure 2.6. $D S\left(K_{1,5}\right)$

\section{CONCLUSION}

In this work, we investigated that the degree splitting of some graphs are square difference graph.

\section{REFERENCES}

[1]. B. Basavangoud, Prashant. V. Patil and Sunil kumar, "Domination in degree splitting graphs", Journal of Analysis and computation, vol 8, No. 1, (2012) ISSN: $0973-2861$.

[2]. J. A. Gallian, "A Dynamic survey of graph labeling", The electronics journal of Combinatories, 17(2010), \# DS6.

[3]. P. Jagadeeswari, K. Manimekalai, K. Ramanathan, "Square Difference Labeling of Some Special Graphs" International journal of Innovative Science and Research Technology, Vol 4, issue 5, May 2019, ISSN No: 2456-2165.

[4]. P. Maya, T. Nicholas, "Degree splitting of some I - Cordial graphs", International journal of Research in Advent Technology, vol 6, No. 8 , (2018), ISSN: $2321-9637$.

[5]. Ponraj. R, S. Somasundaram, "On the degree splitting of some graph", National Academy Science letters 27(2004), 275 - 278.

[6]. Rosa, "On Certain valuation of graph theory of graphs (Rome, July 1966), Golden and Breach. N. Y, Paris (1967) 349 - 355.

[7]. G. Sankari, S. Lawanya "Odd - Even Graceful Labeling of Umbrella and Tadpole Graphs", International Journal of Pure and Applied Mathematics, Vol (114), 6, 2017, 139 - 143.

[8]. J. Shiama, "Square Difference Labeling for some graphs", International journal of Computer Application, 44(4), (2012).

[9]. Siliviya Francis, V. Balaji, "Mean labeling on degree splitting graph

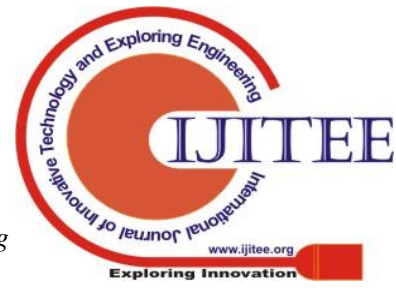


Degree Spilliting Analysis for Polynomials Developed for Electrical Systems

of star graph", International journal of Advances in Applied Mathematics and Mechanics. 5(2), (2017), 25 - 29, ISSN: $2347-2529$.

\section{AUTHORS PROFILE}

P. Jagadeeswari is an Assistant Professor, Department of Science and Humanities, BIHER, Chennai. She is currently working on Graph labeling. She published 7 papers in international journal. 